\title{
The physical and Chemical Impact of Microplastic in The Marine Environment: a Systematic Review
}

\author{
Anis Tatik Maryani*, Yudha Gusti Wibowo, Kerlin Maysatria \\ Postgraduate Program of Environmental Science, Universitas Jambi. \\ *Corresponding Author: anistatik@yahoo.com
}

\begin{tabular}{llll} 
Article history & & \\
\hline Received & Received in revised form & Accepted & Available online \\
31 March 2019 & 30 March 2020 & 31 March 2020 & 31 March 2020
\end{tabular}

\begin{abstract}
Marine environment reported has been decreasing in water quality caused by microplastic. This microparticle generated from contamination of ultraviolet light with plastic debris on the environment. Microplastic has been found in several marine environments and made some problems especially for marine ecosystem, such as beach, river and sea. This article described microplastic source, technique for detection and analysis of microplastic in marine environment, physicochemical of microplastic including physical properties such as particle size, particle shape, crystallinity, etc and chemical properties of microplastic (i.e. toxicity and chemical compounds). This article discusses the impact of microplastic for environment and human health. Thus, this article has described the systematic information about microplastic in the marine environment.
\end{abstract}

Keywords: Microplastic, marine environment, plastic, water quality, impact of microplastic

\section{Introduction}

Surface water has been decreasing in quantity caused by human activities. Lot of pollutants were identified in surface water especially for coastal and marine. Pollutants such as persistent organic pollutants (POPs), pesticides, hydrocarbons, plastic, heavy metals and microplastic impact the surface water ecosystem. The unique characteristics of marine environment make up the physicochemical properties of marine environments. Plastic has been growing up of the municipal waste till 2003 and makes up about $85 \%$ of marine litter. Plastic global production has increased significantly in 2014, the production reported from 1.7 million tonnes in 1950s to 299 million tonnes in 2014 [1]. Lot of marine environments reported that these surface water has been contaminated by microplastic [2]. Microplastic is small fragments of plastics in the ocean, microplastic also found in ocean, estuaries, bodies of fresh water, artic ice, beach, surface waater, marine sediment as well as in marine biota [3].

Microplastic is small fragment of plastic (less than $5 \mathrm{~mm}$ ) and generated under ultraviolet light in low temperatures. Industrial of manufactures and domestic application are majority of microplastic source in the marine environment. Exfoliating facial scrub, resin pellets and toothpastes used in plastic industry (primary microplastic) and those re-formed under ultraviolet radiation generated secondary microplastic These small plastics size enter the marine environment through several activities on land and in the marine environment such as industrial drainage system, wastewater system plants, fishing activity, and another human activities. Microplastic is small size plastic makes them easily to contact and containing the organisms in the marine such as bivavles, plankton, zooplankton, fishes, mussels, shrimps, copepods, lugworms and whales has been reported to high contaminated with microplastic [4]

Several countries confirmed about microplastic contamination such as United State of America (USA) in Laurentian lake and Great lake, North Pacific, Australia, Geoje Island, Mediterania sea including North Pacific Central Gyre, Tokyo Bay, Eastern China, South Sea of Korea with microplastic contamination ranged from $10 \%$ to $98 \%$ [5]. Microplastic also found in deep-sea sediment with smaller size (less than 1 $\mathrm{mm})$. Samples of microplastic collected from southern ocean in depth $2749 \mathrm{~m}$, length $118 \mu \mathrm{m}$ and width 60 $\mu \mathrm{m}$, Nile deep sea fan in depth $1179 \mathrm{~m}$, length $75 \mu \mathrm{m}$ and width $53 \mu \mathrm{m}$, and Porcupine Abyssal Plain in depth $4842 \mathrm{~m}$, length $161 \mu \mathrm{m}$ and width $137 \mu \mathrm{m}$, the microplastic also scanned with Scanning Electron Microscope in every single place [6]. The aims of this article is to describe the source, technics of microplastic analysis, microplastic in the marine environment and physicochemical properties of microplastic and its impact on human health, biota and the environment 


\section{Source of Microplastic}

Recent study reported microplastic has generated from synthetic fibers in atmospheric. This study inform that atmospheric in synthesis fiber has fall out. Total atmospheric was collected on two sampling places, one in urban environment and one in sub-urban environment in 13 month (February 19, 2014 until March 12, 2015) and the one place is in October 3, 2014 until March 12, 2015 in local area around 17900 $\mathrm{km}^{2}$. This study inform that fallout range from 2 to 355 particles $/ \mathrm{m}^{2}$ in each day and average of atmospheric fallout between $110 \pm 96$ particles $/ \mathrm{m}^{2} /$ day and in site two, the atmospheric fallout was around $53 \pm 38$ particles $/ \mathrm{m}^{2} /$ day [7]. Recent study reported that wastewater treatment works (WwTw) is one of microplastic source in aquatic environment. This study reported from River Clyde. Microplastic was measured in different stages of the wastewater process. Microplastic was measured in four site and their microplastic value in day, month and year. This study inform that in site 1, a litter of wastewater has microplastic contaminant about 15.70 atmospheric microplastic (MP) per litter per day, $4097 \pm 1,365$ MP/day in a month and $1495397 \pm 498,395$ million MP/year with percent removal 0 in each day, month and year. Site two produced $8.70( \pm 1.56) \mathrm{MP} / \mathrm{L}$ in a day, $2270( \pm 406) \mathrm{MP} /$ day and $828659( \pm 148,171) \mathrm{MP}$ per year with $44.59 \%$ removal. In site three was produced $3.40( \pm 0.28) \mathrm{MP} / \mathrm{L}, 887( \pm 74) \mathrm{MP} /$ day and $323844( \pm 26,940) \mathrm{MP} /$ year with $78.34 \%$ removal and in last site produced $0.25( \pm 0.04) \mathrm{MP} / \mathrm{L}, 65( \pm 11)$ $\mathrm{MP} /$ day and $23812( \pm 4,041) \mathrm{MP} /$ year with removal percent is 98.41. Site one is influent, site two is grit and grease influent, site three is primary influent and site four is final influent [8]

Microplastic in marine environment also imported from the land, a recent study reported that

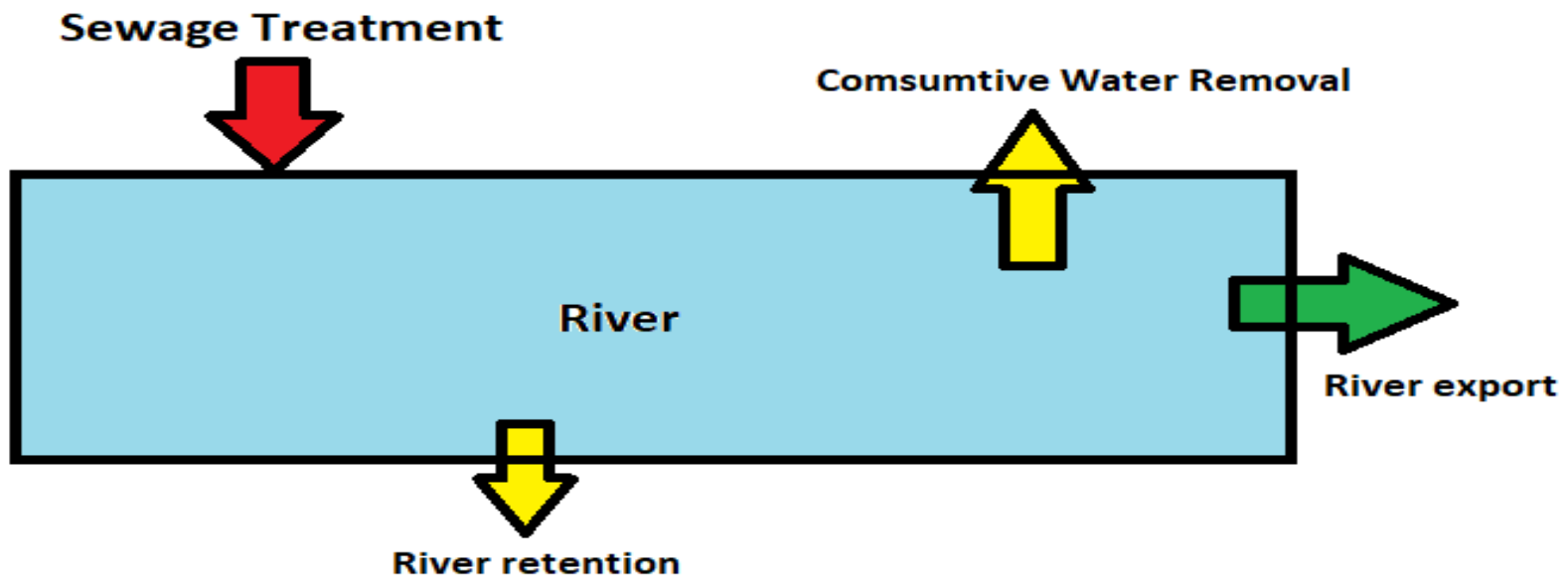

export of micorplastic from the land and its model. Several sources were reported to produce mircroplastic in the environment including personal care products, household dust, laundry, tyre and road wear particles. These materials were exported by rivers to sea. The Global NEWS (Nutrient Export from Watersheds) model was used to identify the microplastic import from the land. This study reported that personal care products has been importing to sea around 0.0071 $\mathrm{kg} /$ capita/year, household dust has been importing to sea around $0.08 \mathrm{~kg} /$ capita/year, laundry inputs is 0.12 $\mathrm{kg} / \mathrm{capita} /$ year and tyre wear is $0.18 \mathrm{~kg} / \mathrm{capita} /$ year [9]. The Global NEWS model can see in Fig. 1. Another source of microplastic is Manucipal Solid Waste (MSW), samples was filtered by stainless-steel sieves with different sizes $(150,75,45$ and $25 \mu \mathrm{m}$. Microplastic was created by extraction in laboratory. Total of 17 different plastic(s) were found in leachate including PE, PP, PVC, PS, ABS, PET, PUR, EVA, PA, PES, EP, PF, PPC, PMMA, ALK, PMDS, PTFE with different concentration between 0.96 items/L until 24.58 items/L [10].

Browne [11] reported the accumulation of microplastic on shorelines worldwide caused by 240 million tonnes of plastic each year. This phenomenon showed that environment will receive some impact from plastic waste. Samples of microplastic were collected from sandy beaches in Australia (Port Douglas and Busselton), Japan (Kyushu), Oman, United Arab Emirates (Dubai), Chile (Vina Del Mar and Punta Arenas), Philippines (Malapascua Island) Portugal (Faro), Azores (Ponta Delgado), USA (Virginia, California), South Africa (Western Cape), Mozambique (Pemba) and UK (Sennon Cove) from 2004 to 2007. Based on this study, researchers found the microplastic contamination in sediment from worldwide [11]

\section{Comsumtive Water Removal}

Figure 1. Schematic overview of microplastic point-source inputs to rivers and export to the river mouth 


\section{Techniques for Analysis and Detection} Microplastic in Marine Environment

New techniques for microplastic analysis and detection has been developed. The methods developed by Claessens [12] explained the extraction of microplastics from sediments in marine environment by elutration and floating. Based on this research design, PVC column was used with length is $147 \mathrm{~cm}$ and diameter of internal is $15 \mathrm{~cm} .500 \mathrm{~mL}$ of sediment will transferred into the column by washing it through the $1 \mathrm{~mm}$ sieve to remove all large debris. The function of sieve is cover prevent contamination with fibers or particles transported to the air. After this step, material will collected on the $35 \mu \mathrm{m}$ sieve subsequently undergoes a sodium iodide extraction. The top layer containing the microplastic is vacuum filtered more than $5 \mu \mathrm{m}$ membrane filter (Whatmen AE98). Thus, microplastic was extracted from the sediment in different sizes and materials.

Two of new methods for microplastic detection and analysis are depuration and acid digestion. These methods can extracting microplastic from animal soft tissue. Sample was collected from Belgian coast. The new development of extraction technique involved the chemical digestion of the soft tissue, using base, acid, oxidizer or mixture of both. Lot of digestion protocols were explored such as organisms were transferred to a $200 \mathrm{~mL}$ conical flask and acid, base or mixture of both in $20 \mathrm{~mL}$. The digestion used nitric acid $22.5 \mathrm{M}$, hydrogen peroxide $32.6 \mathrm{M}$ and sodium hydroxide 52.5 $\mathrm{M}$. The mixture of specific material has prepared by mixing $\mathrm{HNO}_{3}$ with either hypocloric acid or $\mathrm{H}_{2} \mathrm{O}_{2}$ in a $3: 1 \mathrm{v} / \mathrm{v}$ ratio. The protocol consisted of digestion at a specific time and temperature in 1:10 v/v either with hot or cold filtered deionized water [12].

One of recent study reported a method to identify and analysis the microplastic in marine environment from Atlantic and Pacific Ocean. In this study, researchers using FTIR and Raman spectroscopy for definitive identification of individual particle from the plastic, one of powerful instrument to analyze microplastic from the marine and animals in marine environment is Scanning Electron Microscope with Energy Dispersive X-Ray Spectroscopy (SEM-EDX). This instrument allows for large numbers of particles from microplastic quickly and efficiently with less of misidentification errors. In this study SEM-EDX was used to identify and analysis the microplastic from ocean trawl and fish guts [13].

A study from Hong Kong [14] reported that microplastic is a vector to transport heavy metals and organic pollutants to marine animals. The PE, PS and PVC are sources of microplastic marine animal. This research investigated the new method to identify and solve the problem of microplastic from animals in marine environment using perfluorooctanesulfonate (PFOS) and perfluorooctanesulfonamide (FOSA). PFOS and FOSA purchased from Sigma-Aldrich in St. Louis, MO. They used these materials to solve the microplastic in marine animals, X-Ray Diffraction has been used in this study, the pattern of X-Ray Diffraction used to identify pattern of PE, PS and PVC particles and the degree of cristallinity. Thus, there are many instruments can be used to identify and determine the microplastic contamination in the marine environment and its impact. A review of microplastic identification method and instrument was investigated in the marine environment. This methods is visualized in Austrian Danube, Austria, Great Paris, Lake Geneva, Yangtze Estuary, Los Angeles river, San Gabriel river, Coyote Creek and Raritan river, USA. The second method is FTIR in Dutch river delta and Amsterdam canals, Rine river, Theww Gorges Dam, China, Lakes, Wuhan, China. The third method is combination of FTIR-SEM-EDX, which is visualized in Taihu lake, China, Lake Winniping, Canada and else [15]. Study of microplastic detection has been developing in this decade, how to get a valid sample has been developing by lot of researcher, in this millennium era, sampling for microplastic are limited in water sample, sediment samples (beaches, subtidal sediments), extraction of microplastic, size fractionation and sample purification. Visualization of microplastic also limited in visual identification, identification of microplastics by their chemical composition (Density Separation with Subsequent C:H:N Analysis, Pyrolysis-GC/MS, Raman Spectroscopy and IR Spectroscopy) [16].

A study from China reported the microplastic in pacific ocean, sample was collected from surface water of Northwestern Pacific Ocean using the TIOafiiliated oceanographic research vessel XIANG YANG HONG 03, samples were collected 4800 tons. The microplastic sample was treated with NOAA protocol (National Oceanic and Atmospheric Administration). A glass of sample (1 L) were filtered through stacked 5-mm and $0.3 \mathrm{~mm}$ sieve were removed and thoroughly transferred into a litter of clean water with Milli-Q water. The wet peroxide digestion with $\mathrm{H}_{2} \mathrm{O}_{2}$ and $\mathrm{FeSO}_{4}$ was conducted to remove the organic pollutant from the microplastic samples. The sample was transferred to another glass for density isolation using $300 \mathrm{~g} / \mathrm{L} \mathrm{NaCl}$. After that, the supernatant was filtered through $\mathrm{GF} / \mathrm{F}$ Whatman filters. The number, size and color of the microplastics were identified using stereo light microscope and the polymer composition was identified using Senterra II Compact 
Raman Microscope coupled with an optical microscope with a grafting of 1200 lines/mm using 50 x 20 objectives [17].

A study from Hong Kong were identified for more than 500 sandy beach, survey were conducted between $7^{\text {th }}$ July 2014 and $6^{\text {th }}$ September 2014. The method of sampling is survey at each the beach. Samples were conducted in $50 \times 50 \mathrm{~cm}$ square. All of materials will be bring to the lab for the next steps. Each sample was resuspended in a beaker glass with tap water, sample was sieved through a $0.315 \mathrm{~mm}$ sieve. All of the samples were claasified into: (1) organic structure is not containing in the plastic; (2) plastic fibre is equally thick, bending freely and do not taper at two ends; (3) color of plastic homogenous and clear; (4) classified of plastic type; (5) dried in oven at $40{ }^{0} \mathrm{C}$. The size of microlastic each of place were analyzed with statistical analysis. Wilcoxon rank sum test was used to compare the median and mean of the samples (both of east coast and west coast). Spearman's rank correlation coefficients between all samples of microplastic and large plastic debris were determined. [18]. Pollution of microplastic in marine environment including coast and river also given impact for seafood. Tissues from three different animals were analyzed (mussels, velvet crabs and black seabreams). The animals were collected from Bay of Brest in France and stored at $-20{ }^{0} \mathrm{C}$ prior to analysis. Samples with size $5.4 \pm 1.3 \mathrm{~g}$, mean \pm standard deviation were shelled and placed in $250 \mathrm{~mL}$ digestion solution. All of samples were analyzed to identified the weighing, visual, pyr-GC/MS and Raman [19]

Statistical analysis for comparation of microplastic used the assessment of digestion efficiencies following the Eq 1. Digestion efficiencies (\%De) were calculated as follows, where \%De corresponds to the digestion efficiency, DWf and DWfad correspond respectively to the dry weights $(n=5)$ of the "clean" filter before filtration and the filter covered by organic matter and debris after digestion. Finally, Tw corresponds to the average weight of tissues subjected to digestion $(n=50)$. Ueb (Eq. 2) is one of statistical analysis to analyze the result of weight measurement (Eq. 2). Ueb was estimated as follows, with $\mathrm{d}$ being the resolution of analytical balance and e the standard deviation obtained after evaluation of the reproducibility by consecutive weighing $(\mathrm{n}=50)$. Mean values with more than $0.1 \mathrm{mg}$ difference were considered as significantly different.

$$
\begin{aligned}
\% D e & =100-\frac{D W f a d-D W f}{T w} \\
e b & =2 x \sqrt{\left(\frac{d}{2 x \sqrt{3}}\right)^{2}+\left(\frac{e}{\sqrt{3}}\right)^{2}}
\end{aligned}
$$

Eq. 1

Eq. 2

\section{Physicochemical of Microplastic}

Microplastic has uniqe properties based on their types. A study of microplastic in urban wastewater plant informed 1163 micro litter (ML) particles were identified from wastewater. These samples were characterized with stereomicroscope and chemical composition by FT-IR analysis. 17 polymers were identified based on the samples, the polimers are Acrylate (ACRYL), Biopolymer (BPL), High-density polyethylene (HDPE), Low-density polyethylene (LDPE), Melamine (MUF), Methacrylate (MCR), Nylon (NYL), Polyester (PES), Polyethylene propylene (PEP), Polyethylene terephthalate (PET), Polyisobutylene (PIB), Polypropylene (PP), Polystyrene (PS), Polyurethane (PUR), Polyvinyl (PVI), Rubber, Teflon and unidentified polymers [20]. A recent study informed about microplastic on Open Ocean weathered, this study using six samples of PE (type CAS 9002-88-4), three PE pellets were purchased from USA. They included HDPE, MFI of $2.2 \mathrm{~g} / 10 \mathrm{~min}$ (it's same like HDPE-2.2); HDPE pellets with MFI of $12 \mathrm{~g} / 10 \mathrm{~min}$ with melting point around $125-140{ }^{\circ} \mathrm{C}$, density of material is $0.952 \mathrm{~g} / \mathrm{mL}$ at room temperature $\left(25^{\circ} \mathrm{C}\right)$. This study showed the different material generated different fragment of microplastic based on Photo SEM analysis. The spectra of PE present an absorption band at $2914 / \mathrm{cm}$ corresponding with asymmetric and symmetric stretching of $\mathrm{CH}_{2}$ groups. Also in $2847 \mathrm{~cm}$ is an intense, sharp band also corresponding with $\mathrm{CH}_{2}$ groups. The physicochemical of microplastic is different with raw PE, plastic packaging and mesoplastic, based on this study the carbonyl index of each materials are $0(\mathrm{~N}=6)$ for raw PE, $0.2(\mathrm{~N}=38)$ for plastic packaging, $1.2(\mathrm{~N}=11)$ for mesoplastic and $0.4(\mathrm{~N}=43)$ for microplastic. The melting point of raw $\mathrm{PE}$ is more than $144{ }^{\circ} \mathrm{C}$, the melting point of packaging is $141{ }^{\circ} \mathrm{C}$, the melting point of mesoplastic is $140{ }^{\circ} \mathrm{C}$ and microplastic is $142{ }^{\circ} \mathrm{C}$. This study also inform the percent of crystalinity of materials, percent crystalinity for raw PE is $25-53 \%$, packaging is $23-43 \%$, mesoplastic is $25-43 \%$ and microplastic is $40-60 \%$ [21].

Each of different materials of plastic has different characteristics on microplastic. Microplastic from the different materials also tested for elasticity modulus $\left(10^{3} \mathrm{Mpa}\right)$. The PA has better than RA, PVA, AC, PEA and PET. Abundance of microplastic also 
calculated with $R^{2}=0.99$ and $P<0.05$. This study called microplastic as umbrella term that covers particles with various chemical and physical characteristic (physicochemical). This study using microplastic with consistent shape (spherical polyethylene/polystyrene beads) with $1-100 \mu \mathrm{m}$ in size. This study condidered we need to identify and develop the microplastic that what is found in nature to be a relevant environmental [22]

The physical properties of microplastic is particle size. Particle size is an important characteristic of microplastic, its characteristic will consider about interation of particles and biota. Particle size has studied in laboratory with its consider with biota interaction. Microplastic exposure generally use nano size and micro size in the marine environment. Another one of physical properties of microplastic is particle shape, this properties is an important parameter in determining interaction of polymeric particles with biological system in the marine environment. A recent study has highlight this phenomenon, the effect of particle shape on amphipod Hyalella Azteca, reserachers showed the higher toxicity of polypropylene fibers, another study inform that zinc oxide nanosticks induced higher toxicity in zebrafish. Nexr, the physical properties of microplastic is surface are. This physical characteristic considered an interesting parameter because it increases with decreasing particle size. Surface are can be calculated using shaperical equivalent diameter. Polymer crystalline is one of important characteristic of microplastic, this paper was discussed about crystallinity of microplastic from recent study. Crystalinity is an important property because its region consist of more ordered and tightly polymer chain structure. The chemical properties of microplastic are polymer type and additive. Plastics and their associated toxicity generated by leaching pf chemical activity such as residual monomers, solvents, starting substances and catalyst, as well as additive (i.e. dyes, antioxidants, plasticizers, and biocides) incorporated during processing and pompouding [23].

Abundance is one of physicochemical of microplastic, recent study informed the surface abundance of microplastic in Northwesterm Pacific, samples were collected from the 18 stations in this place. A total of 531 counts of microplastic from 18 stations across pelagic zone. The maximum abundance in this place is 4300 items $/ \mathrm{km}^{2}$ and the minimum abundance is 200 items $/ \mathrm{km}^{2}$. Based on this research, the microplastics has different chemical fingerprints according the micro-raman spectra. The size of microplastic in this place were analyzed using NOAA.
$50 \%$ of microplastic size are between $0.5-1.0 \mathrm{~mm}$, $29.8 \%$ of microplastic has medium size $(1-2.5 \mathrm{~mm})$ and $17.6 \%$ are large size $(2.5-5.0 \mathrm{~mm}) .57 .4 \%$ microplastic is white, $22.8 \%$ is transparent, $6.6 \%$ is green, $6.4 \%$ is black, $2.8 \%$ is blue, $2.5 \%$ is yellow, and $1.5 \%$ is purple. SEM was used to analyze the microstructure of microplastic, based on the photo SEM, microplastic has cracks, hollows, and bumps [24]. The polymer composition of microplastic in Pacific Ocean are PP, PES, PS, PE-PP copolymers), PET and PA. The size distribution of microplastic in this location between $<0.3$ and $>5 \mathrm{~mm}$ with majority color is white $(25 \%)$ [17].

Based on recent research, the abundance of microplastic in Ross Sea (Antartica) detected in size more than $60 \mu \mathrm{m}$. In antartica, microplastic has ranged from 0.0032 to 1.18 particles per $\mathrm{m}^{3}$ in seawater with a mean value of $0.17 \pm 0.34$ particle $/ \mathrm{m}^{3}$. The FTIR of microplastic compared with green algae, the FTIR result showed all of microplastic samples has higher panel absorbance than microplastic. Concentration of all samples were lower than those found in ocean worldwide. This study informed that the potential impact arising from activities of the Mario Aucchelli scientific station such as marine activities [25]. A recent study informed about the characteristics and identification of polymers type from microplastic. Fibers is one of most common microplastic type, this material identified about $83 \%$ across all sites, followed by plastic films (around 11\%) and fragments (average $6 \%$ ). Fibers contributed more than $73 \%$ and all aound $1258 \pm 291 \mathrm{par} / \mathrm{kg}$ found at Bostanu. The microplastic found in this area has different characterization based on FTIR analysis. The PE, nylon and PET were found in this place has different size [26].

\section{Microplastic Impact}

Microplastic has been decreasing and being a problem for environment especially for biota. A recent study reported microplastic impact on organisms and larval production. Larval T. gratilla were obtained from National Marine Science Centre, Australia. In this study, researcher showed the effect of microplastic ingestion in Larval growth and survival in marine environment. Commercial polytethylene microspheres with Cospheric UVPMS-BG, 1.004 g.mL density and nominal $10-45 \mu \mathrm{m}$ diameter has been used to identify and analysis microplastics in marine ecosystem. Based on this research highest percentation of larva with microperes in their stomachs was $31 \%$ in the 300 shperes $/ \mathrm{mL}$. This study inform about time contact of microplastic in Larvae, this study reported in different 
times $(0,60,120,180,240,300,360,420$ and 480 minute) [27].

Microplastic also has impacted on the gut barrier, metabolism of mice and microbiota. A study in laboratory scale prepare the $5 \mu \mathrm{m}$ fluorescent polystyrene microplastic and pristine. This study tested in animals. All mice housed in independent cages in an animal room with cycle of twelve house of dark and light. Two groups exposed to $5 \mu \mathrm{m}$ polystyrene microplastic in the concentration 100. For the toxicological test, the polystyrene microplastic has diluted in RO drinking water and the animals were continuously exposed for 42 days. Result of this study informed polystyrene microplastic observed in the guts of mice and could reduce the intestinal mucus secretion because damage the intestinal barrier function. However, in the genus level, total of 15 bacteria significantly changed after contaminated with polystyrene microplastic. Conclusion of this study is polystyrene microplastic induced gut microbiota dybiosis, metabloc disorders in mice and intestinal barrier dysfunction [28]. Thus, based on this research and microplastic impact on mice, its indicated that microplastic can impacted mammals (also human as a mammals).

Microplastic can also contaminated into human food chain and make some negative impacts on human health. The contaminated microplastic in marine environment caused by human product and activities (Fig. 7). Recently, chemical properties of microplastic which are a palpable concern for human health include phthalates, bispenol A (also called BPA), triclosan, brominated flame retardants (BFR) organotins and bishpenone. The information about leaching of additives into biological tissue is limited. A study informed that additives such as nonyphentol and BPA can leach from plastic ingested bt marine environment. Recent information, BPA is the main chemical used as a monomer for polycarbonate plastic. BPE could be used as an antioxidant and as a plasticizer in some polymers [29]. Recent study also reported an impact of microplastic beads and fibers on waterflea (Ceriodaphnia dubia) survival, growth and reproduction, in this study microplastic fibers prepared from cutting the fleece surface from orange fluorescent clothing with composition $100 \%$ of polyester and density of material is $1.38 \mathrm{~g} / \mathrm{cc}$, this material also chopping into small pieces. In this study researcher examined the acute for 48 hours and chronic in 8 days effect of microplastic polyester fibers and PE beads on zooplankton in freshwater (Ceriodaphnia dubia). Based on this study exposure of chronic in lower concentration did not significantly effect on
Ceriodaphnia dubia survival but a dose-dependent effect on reproduction and growth was observed [30].

A wide range of vertebrate and invertebrates have been shown to accumulate the microplastic $(<1$ $\mu \mathrm{m})$. The micro and nano-plastic has the combination effect of their intrinsic toxicity and their surface area, i.e. PVC inhalation dust human can give some negative impacts for human health (e.g. liver damage, cancer and through tissue fibrosis). Degradation of environment has been reported due to microplastic contamination. The trial of laboratory have shown that the organisms has contaminated with the microplastic particles [31]. A research from United Kingdom also reported the ingestion of microplastic by zooplankton. Zooplankton was conducted between November 2011 to October 2012 in coastal site, located in the western English Channel $12 \mathrm{~km}$ south of Plymouth,United Kingdom. Based on this study, researcher found the microplastic in zooplankton and this phenomenon will give negative impact for zooplankton function and health [32].

A recent study also reported the impact of microplastic beads and fibers on waterfla (Ceriodaphnia dubia) survival, growth and reproduction. In this study, they examined the acute and chronic effects of PE microplastic bead on freshwater zooplankton. Based on this study, researcher reported chronic exposure in lower concentration does not give significant impact on survival of Ceriodphnia dubia but a dose-depent effect on reproduction and growth was observed. This study also reported that higher contamination of microplastic given high impact on slower survival, growth and reproduction of Ceriodphnia dubia [30]. A short letter from Proceedings of the National Academy of Sciences of the United States of America reported the letter to understand of microplastic pollution in aquatic ecosystems. They reported the comparison between microplastic concentration used in exposure studies and observed environmental levels. The regression value of this research is $y=3,188 \cdot x^{-2.67} ; 95 \%$. The particle density is $1.04 \mathrm{~g} / \mathrm{cm}^{3}$ [33]. Microplastic also impact on marine organisms and possible to transfer from organism to organism. A study in 2013 reported trophic transfer of microplastic from Mytilus edulis to Carcinus maenas, this study reported that microspheres were found in tissue samples from the stomach, hepatocancreas, ovary and gills. The diameter of microspheres is $5 \mathrm{~mm}$ and has different diameter according the contact time. Based on this study, a microplastic from Mythilus edulis was transferred to Carcinus meanes in laboratory test [34]. Based on this study, we can found the fact that microplastic can 
transfer from the animal to animal. Thus, the negative impact of microplastic has been spreading in marine environment everytime in every single place (including environment to animal and animal to animal).

Lot of study were reported the negative impacts of microplastic. This nano particle size could impact animal, microorganism, water plants and human. Thus, we need to be more responsible to use a plastic bag, do not use the one use plastic bag. This condition also force researcher to find a new material to build a better plastic debris. This innovation will make better environment for all, in addition, the tourism in the beach need to be more care with their environment. The possible transfer of microplastic from agriculture ecosystem has been reported, this phenomenon will give an impact on biodegradation caused by their polymer type. The wastewater treatment also reported as a potential source of microplastic in the aquatic ecosystem. Microplastic from the wastewater treatment found in coastal Gulf of Finland, Baltic Sea. The wastewater treatment around coastal Gulf of Finland has been impacting the sedimentation. Impact of the WWTP around the coastal is micro and nanoparticles of plastic such as black carbon particles, fibber, synthetic particles and ringshaped particles. This study reported the microplastic removed around the coastal. They expected that the abundance of microplastics would be higher in sediments at the discharge sites of WWTP than another site. The water quality in the site has been found 32 particles per liter of sea were using $10 \mu \mathrm{m}$ filter size [35].

Not only for microplastic, the plastic debris also give some negative impacts for environment and animals. Before becoming microplastic, plastic debris also made trouble in marine environment. Several animals also reported snagged, disturbed because of plastic to death. Not only for animal, plastic debris before becoming microplastic also causes unpleasant odors and reduces the beauty of the marine ecosystem. A study from United Kingdom reported 115 marine mammals, 16,754 fish, 312 seabirds and 7 sea turtles disturbed by plastic [36]. This numbers has been growing up each time.

\section{Conclusion}

Microplastic is a small particles from plastic debris in marine environment. Plastic debris has been changed into microplastic particles due to Ultraviolet light. The source of microplastic are agriculture, medical application, personal care product (i.e. toothpaste), laundry, urban and transport infrastructure, erosion and abrasion of synthetic rubber tires, landfill, transportation activity, fishing activity and else. Microplastic in marine environment generated from the plastic debris in marine ecosystem and imported from the land. Impacts of microplastic for human health showed negative impact such as liver damage and cancer. Microplastic also reported made negative impact for microorganism such as larvae and zooplankton, this condition given negative impact for their function and life. Thus, microplastic is a dangerous mico particle from the plastic debris and made negative impacts in marine environment.

\section{Reference}

[1] Auta H S, Emenike C U and Fauziah S H 2017 Distribution and importance of microplastics in the marine environmentA review of the sources, fate, effects, and potential solutions Environ. Int. 102 165-76

[2] Andrady A L 2011 Microplastics in the marine environment Mar. Pollut. Bull. 62 1596-605

[3] Andrady A L 2017 The plastic in microplastics: A review Mar. Pollut. Bull. 119 12-22

[4] Ferreira P, Fonte E, Soares M E, Carvalho F and Guilhermino L 2016 Effects of multistressors on juveniles of the marine fish Pomatoschistus microps: Gold nanoparticles, microplastics and temperature Aquat. Toxicol. 170 89-103

[5] Wibowo Y G, Maryani A T, Rosanti D and Rosarina D 2019 Microplastic in Marine Environment and Its Impact Sainmatika J. Ilm. Mat. dan Ilmu Pengetah. Alam 1681

[6] Van Cauwenberghe L, Vanreusel A, Mees J and Janssen C R 2013 Microplastic pollution in deep-sea sediments Environ. Pollut. 182 495-9

[7] Dris R, Gasperi J, Saad M, Mirande C and Tassin B 2016 Synthetic fibers in atmospheric fallout: A source of microplastics in the environment? Mar. Pollut. Bull. 104 290-3

[8] Murphy F, Ewins C, Carbonnier F and Quinn B 2016 Wastewater Treatment Works (WwTW) as a Source of Microplastics in the Aquatic Environment Environ. Sci. Technol. 50 5800-8

[9] Siegfried M, Koelmans A A, Besseling E and Kroeze C 2017 Export of microplastics from land to sea. A modelling approach Water Res. 127 249-57

[10] He P, Chen L, Shao L, Zhang H and Lü F 2019 Municipal solid waste (MSW)landfill: A source of microplastics? -Evidence of microplastics in landfill leachate Water Res. 159 38-45

[11] Browne M A, Crump P, Niven S J, Teuten E, Tonkin A, Galloway T and Thompson R 2011 
Accumulation of microplastic on shorelines woldwide: Sources and sinks Environ. Sci. Technol. 45 9175-9

[12] Claessens $M$, Van Cauwenberghe L, Vandegehuchte M B and Janssen C R 2013 New techniques for the detection of microplastics in sediments and field collected organisms Mar. Pollut. Bull. 70 227-33

[13] Wang Z M, Wagner J, Ghosal S, Bedi G and Wall S 2017 SEM/EDS and optical microscopy analyses of microplastics in ocean trawl and fish guts Sci. Total Environ. 603-604 616-26

[14] Wang F, Shih K M and Li X Y 2015 The partition behavior of perfluorooctanesulfonate (PFOS) and perfluorooctanesulfonamide (FOSA) on microplastics Chemosphere 119 841-7

[15] Li J, Liu H and Paul Chen J 2018 Microplastics in freshwater systems: A review on occurrence, environmental effects, and methods for microplastics detection Water Res. 137 362-74

[16] Bergmann M, Gutow L and Klages M 2015 Methodology Used for the Detection and Identification of Microplastics-A Critical Appraisal Marine Anthropogenic Litter pp 1447

[17] Pan Z, Liu Q, Sun Y, Sun X and Lin H 2019 Environmental implications of microplastic pollution in the Northwestern Pacific Ocean Mar. Pollut. Bull. 146 215-24

[18] Fok L and Cheung P K 2015 Hong Kong at the Pearl River Estuary: A hotspot of microplastic pollution Mar. Pollut. Bull. 99 112-8

[19] Dehaut A, Cassone A L, Frère L, Hermabessiere L, Himber C, Rinnert E, Rivière G, Lambert C, Soudant P, Huvet A, Duflos G and Paul-Pont I 2016 Microplastics in seafood: Benchmark protocol for their extraction and characterization Environ. Pollut. 215 223-33

[20] Bayo J, Olmos S and López-Castellanos J 2020 Microplastics in an urban wastewater treatment plant: The influence of physicochemical parameters and environmental factors Chemosphere 238

[21] ter Halle A, Ladirat L, Martignac M, Mingotaud A F, Boyron O and Perez E 2017 To what extent are microplastics from the open ocean weathered? Environ. Pollut. 227 167-74

[22] Li L, Su L, Cai H, Rochman C M, Li Q, Kolandhasamy P, Peng J and Shi H 2019 The uptake of microfibers by freshwater Asian clams (Corbicula fluminea) varies based upon physicochemical properties Chemosphere 221
$107-14$

ojs.pps.unsri.ac.id

[23] Lambert S, Scherer C and Wagner M 2017 Ecotoxicity testing of microplastics: Considering the heterogeneity of physicochemical properties Integr. Environ. Assess. Manag. 13 470-5

[24] Pan Z, Guo H, Chen H, Wang S, Sun X, Zou Q, Zhang Y, Lin H, Cai S and Huang J 2019 Microplastics in the Northwestern Pacific: Abundance, distribution, and characteristics Sci. Total Environ. 650 1913-22

[25] Cincinelli A, Scopetani C, Chelazzi D, Lombardini E, Martellini T, Katsoyiannis A, Fossi M C and Corsolini S 2017 Microplastic in the surface waters of the Ross Sea (Antarctica): Occurrence, distribution and characterization by FTIR Chemosphere 175 391-400

[26] Naji A, Esmaili Z and Khan F R 2017 Plastic debris and microplastics along the beaches of the Strait of Hormuz, Persian Gulf Mar. Pollut. Bull. 114 1057-62

[27] Kaposi K L, Mos B, Kelaher B P and Dworjanyn S A 2014 Ingestion of microplastic has limited impact on a marine larva Environ. Sci. Technol. 48 1638-45

[28] Jin Y, Lu L, Tu W, Luo T and Fu Z 2019 Impacts of polystyrene microplastic on the gut barrier, microbiota and metabolism of mice $S c i$. Total Environ. 649 308-17

[29] Karbalaei S, Hanachi P, Walker T R and Cole M 2018 Occurrence, sources, human health impacts and mitigation of microplastic pollution Environ. Sci. Pollut. Res. 25 36046-63

[30] Ziajahromi S, Kumar A, Neale P A and Leusch F D L 2017 Impact of Microplastic Beads and Fibers on Waterflea (Ceriodaphnia dubia) Survival, Growth, and Reproduction: Implications of Single and Mixture Exposures Environ. Sci. Technol. 51 13397-406

[31] Weber J C 1968 Calcinosis Cutis: Metabolic, Sweat, Histochemical, X-Ray Diffraction, and Electron Microscopic Study Arch. Dermatol. 98 219-29

[32] Cole M, Lindeque P, Fileman E, Halsband C, Goodhead R, Moger J and Galloway T S 2013 Microplastic ingestion by zooplankton Environ. Sci. Technol. 47 6646-55

[33] Lenz R, Enders K and Nielsen T G 2016 Microplastic exposure studies should be environmentally realistic Proc. Natl. Acad. Sci. U. S. A. 113 E4121-2

[34] Farrell P and Nelson K 2013 Trophic level transfer of microplastic: Mytilus edulis (L.) to 
Carcinus maenas (L.) Environ. Pollut. 177 1-3

[35] Talvitie J, Heinonen M, Pääkkönen J P, Vahtera E, Mikola A, Setälä O and Vahala R 2015 Do wastewater treatment plants act as a potential point source of microplastics?
Preliminary study in the coastal Gulf of Finland, Baltic Sea Water Sci. Technol. 72 1495-504

[36] Gall S C and Thompson R C 2015 The impact of debris on marine life Mar. Pollut. Bull. 92 170-9 